\title{
Design and development of a new lentiviral based anti-HIV therapeutic vaccine
}

\author{
M Rodriguez, E Sarry, A Bejanariu, L Casaban, S Abdalla, E Sabbah-Petrover, C Bauche \\ From AIDS Vaccine 2012 \\ Boston, MA, USA. 9-12 September 2012
}

\section{Background}

Theravectys develops a new generation of prophylactic and therapeutic vaccines using optimized lentiviral vectors. It's most advanced product, a therapeutic anti-HIV vaccinal treatment, will enter clinical Phase I/II within a few weeks. This vaccination will allow seropositive patients to gain an immunological status identical to the so-called "Functional Cured" patients who develop an efficient immunological response capable of controlling the infection without therapy.

\section{Methods}

Vaccine candidates are integrative and self-inactivated live-recombinant lentiviral vectors. They encode an HIV antigen, under the regulation of a patented promoter that is preferentially induced in APC (generating of a strong, specific and long lasting $\mathrm{T}$-cell immune response), and showing a basal level expression in all cells (allowing their elimination by the settled immune response).

Furthermore, Theravectys developed a vaccination regimen based on iterative immunizations with lentivectors encoding the same HIV transgene, relying on different VSV-G serotypes for pseudotyping without generating cross-neutralizing antibodies. These candidates were classified as "Live recombinant vectored vaccines" (EMA, 2011).

\section{Results}

Theravectys set up an innovative manufacturing process combining high production yields, impurity profiles compatible with direct injections into humans and high immunogenicity.

Pilot and GMP batches have been manufactured and GLP preclinical studies (amongst which biodistribution, shedding and toxicity) performed, that showed the

\footnotetext{
Theravectys, Paris, France
}

\section{and take full advantage of:}

- Convenient online submission

- No space constraints or color figure charges

- Immediate publication on acceptance

- Inclusion in PubMed, CAS, Scopus and Google Scholar

- Research which is freely available for redistribution
- Thorough peer review 